\title{
Phloem-based resistance to green peach aphid is controlled by Arabidopsis PHYTOALEXIN DEFICIENT4 without its signaling partner ENHANCED DISEASE SUSCEPTIBILITY1
}

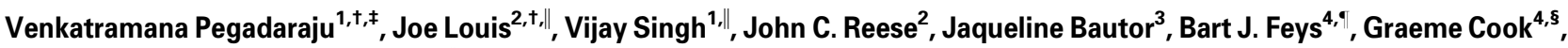 \\ Jane E. Parker ${ }^{3, *}$ and Jyoti Shah ${ }^{1, *, \|}$ \\ ${ }^{1}$ Division of Biology and Molecular Cellular and Developmental Biology Program, \\ ${ }^{2}$ Department of Entomology, Kansas State University, Manhattan, KS 66506, USA, \\ ${ }^{3}$ Max-Planck Institute for Plant Breeding Research, Department of Plant-Microbe Interactions, Carl von Linné Weg 10, \\ 50829 Cologne, Germany, and \\ ${ }^{4}$ Sainsbury Laboratory, John Innes Centre, Colney Lane, Norwich NR4 7UH, UK
}

Received 9 April 2007; revised 11 June 2007; accepted 21 June 2007.

*For correspondence (fax +1 785532 6653; email shah@ksu.edu or fax +49 2215062 353; email parker@mpiz-koeln.mpg.de).

${ }^{\dagger}$ These authors contributed equally to this work.

${ }^{\ddagger}$ Present address: Monsanto, Mystic, CT 06355, USA.

Present address: Department of Biological Sciences, Imperial College London, South Kensington Campus, London SW7 2AZ, UK.

${ }^{\S}$ Present address: NHS National Services Scotland, Edinburgh EH12 9EB, UK.

"Present address: Department of Biological Sciences, University of North Texas, Denton, TX 76203, USA.

\begin{abstract}
Summary
Green peach aphid (GPA) Myzus persicae (Sülzer) is a phloem-feeding insect with an exceptionally wide host range. Previously, it has been shown that Arabidopsis thaliana PHYTOALEXIN DEFICIENT4 (PAD4), which is expressed at elevated levels in response to GPA infestation, is required for resistance to GPA in the Arabidopsis accession Columbia. We demonstrate here that the role of PAD4 in the response to GPA is conserved in Arabidopsis accessions Wassilewskija and Landsberg erecta. Electrical monitoring of aphid feeding behavior revealed that PAD4 modulates a phloem-based defense mechanism against GPA. GPA spends more time actively feeding from the sieve elements of pad4 mutants than from wild-type plants, and less time feeding on transgenic plants in which PAD4 is ectopically expressed. The activity of PAD4 in limiting phloem sap uptake serves as a deterrent in host-plant choice, and restricts aphid population size. In Arabidopsis defense against pathogens, all known PAD4 functions require its signaling and stabilizing partner EDS1 (ENHANCED DISEASE SUSCEPTIBILITY1). Bioassays with eds1 mutants alone or in combination with pad4 and with plants conditionally expressing PAD4 under the control of a dexamethasone-inducible promoter reveal that PAD4modulated defense against GPA does not involve EDS1. Thus, a PAD4 mode of action that is uncoupled from EDS1 determines the extent of aphid feeding in the phloem.
\end{abstract}

Keywords: Myzus persicae, plant defense, insect resistance, senescence, stress.

Introduction

Aphids are phloem-feeding insects that use their stylet-like mouthparts to obtain plant sap (Pollard, 1973). Aphids limit plant productivity by manipulating resource allocation patterns in the host plant (Dixon, 1998) and vectoring plant viruses (Kennedy et al., 1962; Matthews, 1991). Plants have evolved multiple mechanisms to defend themselves against aphids, including antibiotic factors restricting insect fecundity and anti-xenotic factors deterring insects from settling on the host and feeding. These defense mechanisms can be exerted at various stages of plant-aphid interaction. They can be employed externally when the aphid probes the plant surface, in the internal tissue layers when the aphid stylet finds its way to the sieve elements, and during the sieve element phase (SEP) when the aphid taps into sieve elements. For example, glandular trichomes present on leaf surfaces produce volatile and non-volatile metabolites that affect aphid behavior and performance (Neal et al., 1990), while tissue damage that occurs during stylet penetration 
causes the release of thiocyanates in Brassica species that are toxic to some aphids (Rask et al., 2000). Also, the sealing of sieve elements in response to aphid stylet penetration, presumably because of coagulation of phloem proteins and callose deposition, can have a direct impact on sap availability to the aphid (Will and van Bel, 2006). In a susceptible host, aphids are able to suppress mechanisms that trigger sealing of sieve elements, thus allowing the insect to feed from one site for a period of hours to days (Tjallingii, 2006; Will and van Bel, 2006).

Aphids secrete two types of saliva into the plant host (Miles, 1987). A gelling saliva, which is first secreted before stylet insertion and then continuously after penetration of the plant surface, envelops the stylet and seals the wound inflicted by stylet penetration (Tjallingii, 2006). This may prevent the release of host factors that promote plugging of sieve plates upon stylet insertion (Will and van Bel, 2006). In contrast, a watery saliva that is continuously secreted during feeding may interact with phloem proteins to prevent their coagulation (Will and van Bel, 2006). Salivary secretions may also contain effectors that modulate plant defense responses (Miles, 1999). For example, the action of salivary polysaccharases on plant cell walls could release oligosaccharides that elicit plant defenses. Alternatively, polyphenol oxidases and peroxidases present in watery saliva are likely to detoxify phenolic allelochemicals and hydrogen peroxide, respectively, produced by the plant host.

The polyphagous green peach aphid (GPA) Myzus persicae (Sülzer) (Hemiptera: Aphididae) has an exceptionally wide host range covering more than 50 families of plants (Blackman and Eastop, 2000). GPA feeding results in the activation of premature leaf senescence in Arabidopsis thaliana, characterized by expression of the SENESCENCE ASSOCIATED GENES SAG13, SAG21 and SAG27, chlorosis and cell death (Pegadaraju et al., 2005). The activation of premature leaf senescence correlates with the ability of Arabidopsis to limit GPA population size. GPA numbers were diminished on the hypersenescent ssi2 and cpr5 mutants compared to wild-type (WT) plants (Pegadaraju et al., 2005). In contrast, delayed activation of premature leaf senescence was accompanied by an increase in GPA numbers on the Arabidopsis pad4 (phytoalexin deficient4) mutant compared to WT (Pegadaraju et al., 2005). PAD4 controls the synthesis of defense signals including the phenolic molecule salicylic acid (SA) and the indole derivative camalexin in resistance to invasive pathogens (Bartsch et al., 2006; Glazebrook et al., 1997; Jirage et al., 1999; Zhou et al., 1998). Genetic analysis, however, has pointed to a role of PAD4 in defense against GPA that is independent of SA and camalexin (Pegadaraju et al., 2005).

PAD4 encodes a nucleo-cytoplasmic protein that has sequence similarity to lipases (Feys et al., 2001, 2005; Jirage et al., 1999). In Arabidopsis, all of the defense signaling activities of $P A D 4$ identified so far were in combination with
EDS1 (ENHANCED DISEASE SUSCEPTIBILITY1), which encodes a structurally related protein that is also distributed between the cytoplasm and nucleus (Falk et al., 1999; Feys et al., 2005). EDS1 interacts with PAD4 in yeast and plant extracts and is required for accumulation of PAD4 protein (Feys et al., 2001, 2005). Another lipase-like protein, SAG101 (SENESCENCE ASSOCIATED GENE101) (He and Gan, 2002), has been identified as an additional component of the EDS1 defense pathway that accumulates in the nucleus and interacts with the EDS1 protein in this compartment (Feys et al., 2005). SAG101 is partially redundant with PAD4 in Arabidopsis resistance to pathogens. The presence of spatially distinct EDS1-PAD4 and EDS1-SAG101 complexes inside the cell suggests that EDS1 functions as an adaptor for PAD4 and SAG101 in a defense signal relay (Feys et al., 2005). PAD4 and EDS1 are also needed for transmission of defense signals to cells beyond the initial sites of pathogen infection (Rustérucci et al., 2001; Wiermer et al., 2005).

In this study, we demonstrate that PAD4 is necessary to control the level of GPA feeding activity in the phloem. The $P A D 4$-mediated resistance involves both antibiotic and antixenotic factors and operates independently of both EDS1 and SAG101.

\section{Results}

Ectopic expression of Arabidopsis PAD4 confers enhanced resistance to GPA

Previously, it was shown that PAD4 transcripts accumulated in leaves of WT Arabidopsis as early as $3 \mathrm{~h}$ post-infestation (hpi) with GPA (Pegadaraju et al., 2005). Also, no-choice bioassays with WT (Col-0) and pad4-1 mutant plants revealed that PAD4 is needed to promote the antibiosis that decreases GPA reproduction (Pegadaraju et al., 2005). To investigate further the role of PAD4 in aphid resistance, we studied the impact of ectopic expression of PAD4 from the CaMV 35S promoter on the plant response to GPA. Several independent 35S:PAD4 transgenic lines were created in the pad4-5 null mutant in accession Ws-0 (see Experimental procedures), and therefore the PAD4 mRNA accumulating in these plants is derived only from the transgene. As shown in Figure $1(\mathrm{a}, \mathrm{b})$, ectopic expression of PAD4 mRNA in one representative 35S:PAD4 line did not cause enhanced accumulation of SAG13 and SAG21 mRNAs or lead to spontaneous cell death in leaves. However, the GPA-feeding induced accumulation of SAG13 and SAG21 transcripts was faster in leaves of 35S:PAD4 plants than in WT. These transcripts were detected as early as $3 \mathrm{hpi}$ in GPA-infested leaves of the 35S:PAD4 line, compared to $12 \mathrm{hpi}$ in GPAinfested WT leaves. Cell death was also induced more rapidly in GPA-infested 35S:PAD4 leaves than in WT. Occasional clusters of dead cells were observed as early as $6 \mathrm{hpi}$ (data not shown) and were abundant in 35S:PAD4 leaves at $24 \mathrm{hpi}$, 


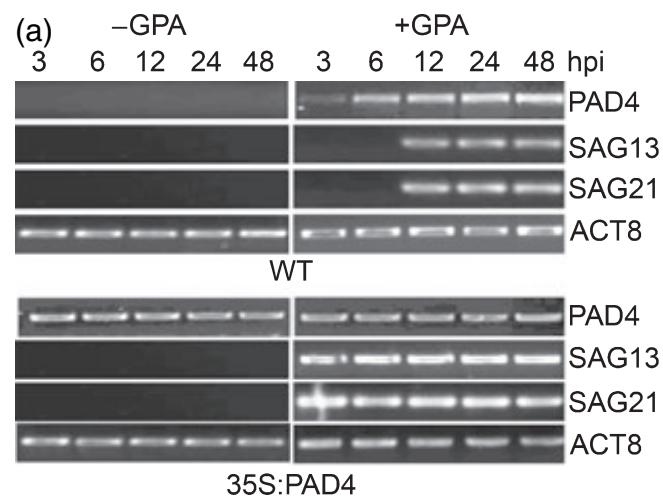

(b)
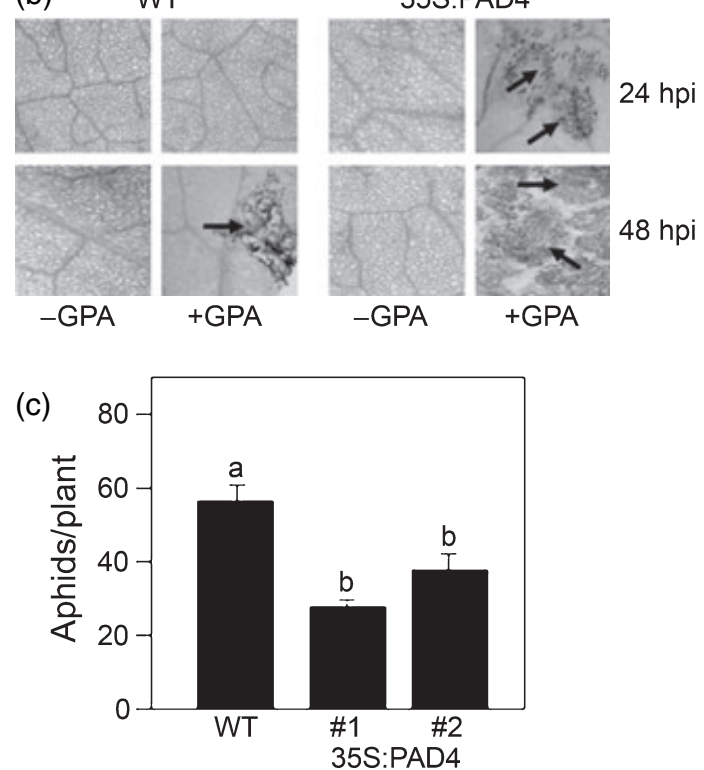

Figure 1. Ectopic expression of PHYTOALEXIN DEFICIENT4 (PAD4) triggers a more rapid response and confers heightened resistance to green peach aphid (GPA) compared with wild-type.

(a) Reverse transcription-polymerase chain reaction (RT-PCR) analysis of PAD4, SAG13 and SAG21 and ACT8 expression in leaves of wile-type (WT) accession Ws-0 (upper panel) and a transgenic 35S:PAD4 plant line 1 (lower panel) that ectopically expresses PAD4. RT-PCR was performed on RNA extracted from non-infested (-GPA) and GPA-infested (+GPA) plants at 3,6, 12,24 and $48 \mathrm{hpi}$. The ACT8 gene served as a control for RNA quality in the RTPCR reaction.

(b) Trypan blue staining of leaves from non-infested (-GPA) and GPA-infested (+GPA) WT and 35S:PAD4 line 1 at 24 and $48 \mathrm{hpi}$. The arrows indicate areas containing intensely stained dead cells.

(c) Comparison of GPA numbers on WT Ws- 0 and two independently derived 35S:PAD4 lines in a no-choice bioassay. The numbers of GPA were counted 2 days after infestation with 20 adult apterous aphids. All values are means for 15 plants \pm SE. Different letters above the bars indicate values that are significantly different $(P<0.05)$ from each other by Student's $t$-test.

whereas cell death was first observed at $48 \mathrm{hpi}$ in GPAinfested WT leaves (Figure 1b). In a no-choice bioassay, numbers of GPA were significantly lower on two independent 35S:PAD4 transgenic lines compared to WT (Figure 1c). We conclude that increased PAD4 expression enhances antibiosis to GPA. (a)
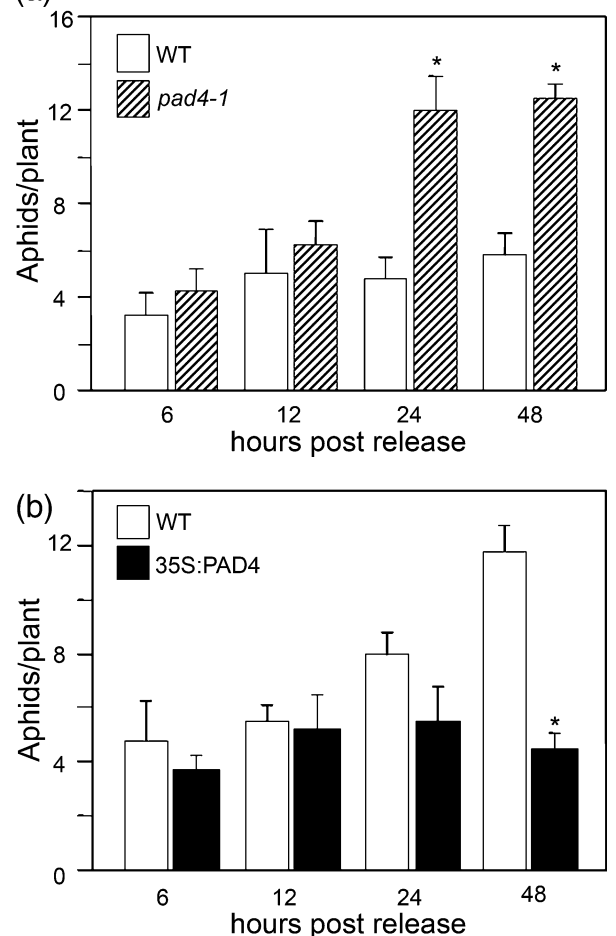

Figure 2. PHYTOALEXIN DEFICIENT4 (PAD4) promotes anti-xenosis to green peach aphid (GPA).

(a) Choice test comparison of GPA preference for wild-type (WT) Col-0 versus pad4-1 mutant plants.

(b) Choice test comparison of GPA preference for WT Ws-0 versus 35S:PAD4 plants.

GPA numbers on a minimum of four plants of each genotype were analyzed for each time point. The means were separated using paired $t$-test $(P<0.05)$. Asterisks indicate significant differences between the pad4-1 or 35S:PAD4 plant and the corresponding WT at that time point.

\section{PAD4 promotes anti-xenosis to GPA}

To determine whether anti-xenotic (deterrent) factors are also involved in PAD4-mediated Arabidopsis defense against GPA, host choice by the aphid was studied. Adult apterous (wingless) insects were given the choice of feeding on WT (Col-0) or pad4-1 mutant plants by releasing 20 insects equidistant from WT and pad4- 1 plants grown in the same pot. The number of adult insects that had settled on plants was monitored over a $48 \mathrm{~h}$ period. The numbers of GPA that had settled on the WT plant remained relatively constant between 12-48 $\mathrm{h}$ after release (Figure 2a). In contrast, the number of GPA that had settled on the pad4-1 mutant gradually increased until $24 \mathrm{~h}$ after release. At 24 and $48 \mathrm{~h}$ after release, GPA showed a significant preference for the pad4- 1 mutant over WT $(P<0.05)$. When given a choice between the WT and 35S:PAD4 line 1, GPA preferred the WT plant $(P<0.05)$ (Figure $2 \mathrm{~b})$. These data indicate that $P A D 4$ promotes anti-xenosis in addition to antibiosis to GPA in Arabidopsis. 
Table 1 Mean time (h) \pm SE spent by green peach aphid (GPA) on various activities on wild type (WT) and phytoalexin deficient4 (pad4-1) plants during $8 \mathrm{~h}$ of recording time

\begin{tabular}{lcc}
\hline Parameters & WT (Col-0) & pad4-1 \\
\hline $\begin{array}{l}\text { Time to first probe } \\
\text { Time to first sieve } \\
\text { element phase (SEP) }\end{array}$ & $0.32 \pm 0.13$ & $0.32 \pm 0.14$ \\
$\begin{array}{l}\text { Total duration of } \\
\text { pathway phase }\end{array}$ & $4.62 \pm 0.37$ & $3.88 \pm 0.35$ \\
$\begin{array}{l}\text { Sum of SEP in a total of } \\
8 \text { h recording time }\end{array}$ & $0.69 \pm 0.14$ & $2.39 \pm 0.29^{*}$ \\
$\begin{array}{l}\text { Available SEP from the } \\
\text { beginning of the first }\end{array}$ & $5.36 \pm 0.41$ & $5.79 \pm 0.27$ \\
$\begin{array}{l}\text { SEP until the end of } \\
\text { recording time }\end{array}$ & & \\
$\begin{array}{l}\text { Percentage of available } \\
\text { SEP actually spent in SEP }\end{array}$ & $13.77 \pm 0.02$ & $42.86 \pm 0.05^{*}$ \\
\hline
\end{tabular}

*Significantly different from the WT accession Col-0 $(P<0.05)$.

${ }^{a}$ Available SEP was used to calculate the percentage of available SEP actually spent in SEP. For example, if the GPA reaches the SEP after $4 \mathrm{~h}$ from the start of the experiment, and continues to the end of the recording time $(8 \mathrm{~h})$, the value is $100 \%$. If the GPA reaches the SEP after $6 \mathrm{~h}$ from the start of the experiment and continues to the end of the recording time ( $8 \mathrm{~h})$, the value is also $100 \%$, but it exhibits lower total SEP.

\section{PAD4 is required for phloem-based resistance to GPA}

To study which aphid feeding stages are affected by PAD4 expression, the electrical penetration graph (EPG) technique was utilized to compare GPA behavior between WT (Col-0) and pad4-1 mutants, and between WT (Ws-0) and 35S:PAD4 transgenic plants. A representative EPG waveform produced by GPA probing on a WT (Col-0) plant is shown in Figure S1. Electrically recorded stylet penetration activities were categorized into various waveforms, and the mean time spent on various activities documented (Tables 1 and 2). Parameters measured include the time to first probe, total duration of pathway phase (penetrating between cells), time to reach first sieve element phase (SEP) when the stylet is located in a sieve element, sum of the duration of all SEPs in a total of $8 \mathrm{~h}$ recording time, and the proportion of available SEP from the beginning of the first SEP until the end of the recording. GPA spent similar amounts of time on average for the time to first probe, total duration of pathway phase and time to reach first SEP on WT (Col-0) and pad4-1 mutants (Table 1), and on WT (Ws-0) and 35S:PAD4 plants (Table 2). The similarity of these GPA behavioral parameters on the various plant lines suggests that neither surface features nor cell-wall properties play a decisive role in $P A D 4$-mediated resistance to this aphid. Measurements of other parameters such as the sum of SEP duration in a total of $8 \mathrm{~h}$ of recording time and the percentage of available SEP actually spent in SEP, however, revealed a significant difference between pad4-1 and WT (Table 1). GPA spent more time in SEP on pad4-1 plants
Table 2 Mean time (h) \pm SE spent by green peach aphid (GPA) on various activities on wild type (WT) and 35S:PHYTOALEXIN DEFICIENT4 (PAD4) transgenic plants during $8 \mathrm{~h}$ of recording time

\begin{tabular}{|c|c|c|}
\hline Parameters & WT (Ws-0) & 35S:PAD4 line 1 \\
\hline Time to first probe & $0.35 \pm 0.15$ & $0.42 \pm 0.27$ \\
\hline $\begin{array}{l}\text { Time to first sieve } \\
\text { element phase (SEP) }\end{array}$ & $3.76 \pm 0.49$ & $4.92 \pm 0.63$ \\
\hline $\begin{array}{l}\text { Total duration of } \\
\text { pathway phase }\end{array}$ & $4.55 \pm 0.39$ & $4.05 \pm 0.48$ \\
\hline $\begin{array}{l}\text { Sum of SEP in a total of } \\
8 \mathrm{~h} \text { recording time }\end{array}$ & $1.14 \pm 0.24$ & $0.42 \pm 0.13^{*}$ \\
\hline $\begin{array}{l}\text { Available SEP from the } \\
\text { beginning of the first } \\
\text { SEP until the end of } \\
\text { recording time }\end{array}$ & $4.24 \pm 0.49$ & $3.08 \pm 0.63$ \\
\hline $\begin{array}{l}\text { Percentage of available } \\
\text { SEP actually spent in SEPa }\end{array}$ & $26.96 \pm 0.06$ & $15.45 \pm 0.05^{*}$ \\
\hline
\end{tabular}

* Significantly different from the WT accession Ws-0 $(P<0.05)$.

${ }^{\text {a }}$ See Table 1 for details of percentage SEP calculations.

compared to WT Col-0 $\left(\chi^{2}=21.65\right.$, d.f. $\left.=1, P<0.05\right)$, reflecting more time spent feeding on the phloem sap of pad4-1. Moreover, the percentage of available SEP actually spent in SEP was greater on pad4- 1 than on WT $\left(\chi^{2}=20.65\right.$, d.f. $=1, P<0.05)$ suggesting that GPA consumes more photoassimilates from the pad4-1 mutant.

Consistent with an effect of PAD4 on aphid feeding, GPA spent significantly less time in SEP on 35S:PAD4 transgenic plants compared to WT Ws-0 (Table 2) $\left(\chi^{2}=7.9\right.$, d.f. $=1$, $P<0.05)$. Also, the percentage of available SEP actually spent in SEP was lower on the 35S:PAD4 transgenic plant than on WT $\left(\chi^{2}=5.08\right.$, d.f. $\left.=1, P<0.05\right)$. These results support the hypothesis that Arabidopsis PAD4 regulates phloem-based resistance against GPA. The PAD4-dependent anti-xenotic effect observed in the choice test (Figure 2a,b) could derive from a PAD4-mediated limitation on phloem sap uptake by GPA.

\section{PAD4-conditioned resistance to GPA is independent of EDS1 and SAG101}

In leaves, the activity of PAD4 in plant defense against pathogens is within an EDS1-regulated pathway (Feys et al., 2005). We therefore tested whether the PAD4 activity found here that restricts GPA feeding from phloem also depends on EDS1. EDS1 transcripts accumulated to a higher level in GPA-infested leaves than non-infested leaves of WT plants (Figure 3). The increase in EDS1 expression in GPA-infested plants mirrored that of PAD4, with both mRNAs accumulating to higher levels than in control non-infested plants by $3 \mathrm{hpi}$. A no-choice test was performed to evaluate GPA performance on an eds 1 RNAi line in accession Col-0 in which the endogenous EDS1 gene was stably silenced using double-stranded RNA interference technology (Feys et al., 


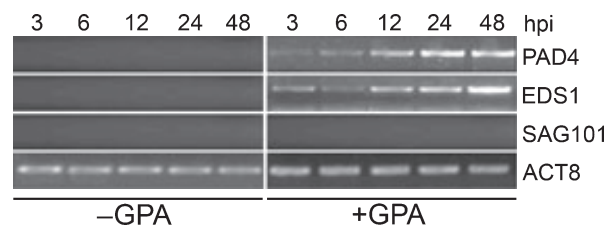

Figure 3. EDS1 expression is induced in response to green peach aphid (GPA) infestation.

Real time-polymerase chain reaction (RT-PCR) analysis of PAD4, EDS1, SAG101 and ACT8 expression in leaves of non-infested (-GPA) and GPAinfested (+GPA) WT Col-0 plants. RT-PCR was performed on RNA extracted from leaves at $3,6,12,24$ and $48 \mathrm{hpi}$. ACT8 served as a control for RNA quality in the RT-PCR reaction.

2005). As controls, GPA performance on WT Col-0 plants and the pad4-1 mutant was monitored. As expected, the numbers of GPA were higher on the pad4-1 mutant than the WT (Figure 4a). However, GPA numbers on the eds1 RNAi line were comparable to those on WT plants, suggesting that EDS1 is not important for plant defense against GPA.

Arabidopsis accession Col-0 expresses an EDS1-like gene that contributes to the total EDS1 activity (Feys et al., 2005). Hence, GPA performance was assessed on the eds 1-1 and eds1-2 null mutants whose corresponding WT accessions Ws- 0 and Ler, respectively, lack a functional EDS1-like gene. GPA performance was also assessed on the pad4 null mutants, pad4-5 and pad4-2, in the Ws-0 and Ler backgrounds, respectively. The numbers of GPA on the eds1-1 (Figure 4b) and eds1-2 (Figure 4c) mutants were comparable to those on WT, whereas the GPA numbers on the pad4-5 and pad4-2 mutants were higher. GPA numbers on the pad4-5 eds 1-1 double mutant were similar to those on the pad4-5 single mutant (Figure 4b). Also, GPA feedinginduced accumulation of SAG13 and SAG21 transcripts and cell death were unaffected in the eds 1 RNAi line (Figure S2).

The discovery of an EDS1-independent activity of PAD4 in aphid resistance was surprising as PAD4 protein accumulation in soluble leaf extracts requires EDS1, and all detectable PAD4 is associated with EDS1 (Feys et al., 2005). We tested further whether PAD4-mediated defense against GPA is uncoupled from EDS1 in Arabidopsis by comparing the responses of stable transgenic pad4-5 and pad4-5 eds 1-1 lines expressing PAD4 (denoted d-P4) under the control of a Dex-inducible promoter (see Experimental procedures). As shown in Figure 5 (a), PAD4 mRNA was not detectable in pad4-5 d-P4 and pad4-5 eds 1-1 d-P4 plants pre-treated with water, nor in a pad4-5 transgenic line containing the empty vector (d-C), 2 days after infestation with GPA. PAD4 transcripts accumulated in GPA-infested leaves of pad4-5 d-P4 and pad4-5 eds 1-1 d-P4 transgenic plants but not in pad4-5 $\mathrm{d}-\mathrm{C}$ leaves that were treated with Dex, confirming the Dexinducibility of the d-P4 transgene. As expected, PAD4 mRNA derived from the endogenous $P A D 4$ gene was expressed in both water- and Dex-treated GPA-infested WT and eds1-1
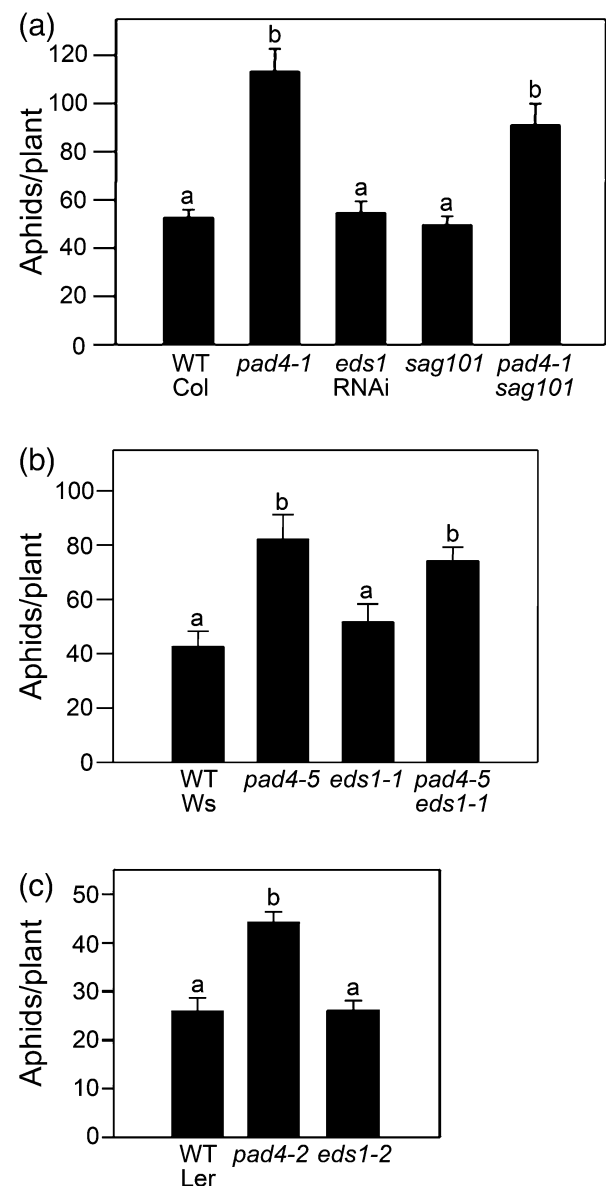

Figure 4. EDS1 and SAG101 are not required for Arabidopsis defense against green peach aphid (GPA).

(a) GPA numbers on wild-type (WT) Col-0, pad4-1, eds1 RNAi, sag101 and pad4-1 sag 101 plants.

(b) GPA numbers on WT Ws-0, pad4-5, eds 1-1 and pad4-5 eds1-1 plants. (c) GPA numbers on WT Ler, pad4-2 and eds1-2 plants.

The numbers of aphid in the no-choice assays were calculated 2 days after infestation of each plant with 15 GPA. All values are means from a minimum of 10 plants \pm SE. Different letters above the bars indicate values that are significantly different $(P<0.05)$ from each other by Student's $t$-test.

mutant plants but not in the non-transgenic pad4-5 mutant. In a no-choice bioassay, GPA numbers were higher on all water-treated plants that contained the pad4-5 mutant allele compared with water-treated WT and eds 1-1 mutant plants (Figure 5b). In contrast, numbers of GPA were lower on Dextreated pad4-5 d-P4 plants, demonstrating the ability of the Dex-inducible PAD4 construct to complement pad4-5 in aphid resistance. Significantly, Dex-induced expression of $P A D 4$ also resulted in lower GPA numbers on pad4-5 eds 1-1 d-P4 plants. As eds1-1 is a null mutant allele, these results provide strong evidence that PAD4 can function without EDS1 in Arabidopsis defense against GPA.

Previously, SAG101 was shown to modulate PAD4 protein levels and possess signaling activity that is partially redundant with PAD4 in resistance to pathogens (Feys et al., 2005). 

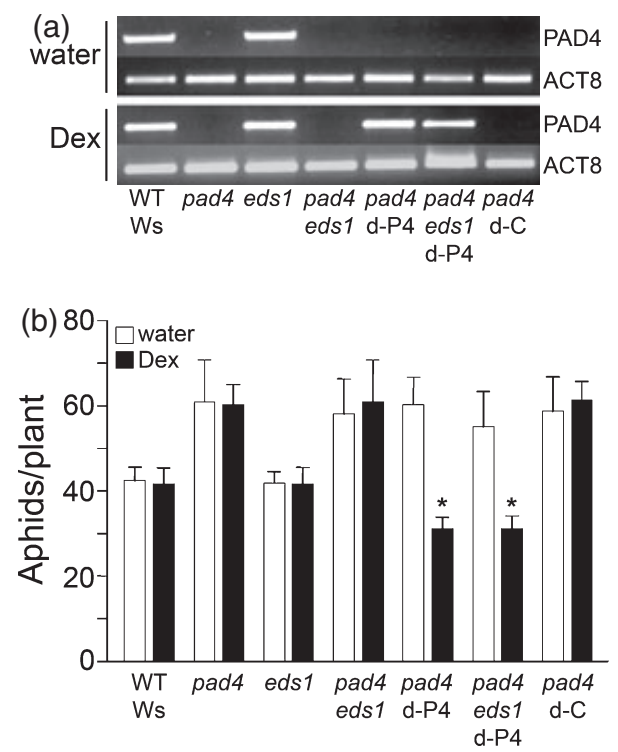

Figure 5. EDS1 is not required for PHYTOALEXIN DEFICIENT4 (PAD4)-mediated restriction of green peach aphid (GPA) infestation.

(a) Real time-polymerase chain reaction analysis of PAD4 and ACT8 expression in GPA-infested leaves of WT Ws-0, pad4-5, eds 1-1, pad4-5 eds 1-1, and pad4-5 or pad4-5 eds 1-1 plants containing the Dex-inducible PAD4 transgene $\mathrm{d}-\mathrm{P} 4$, or pad4-5 plants containing the empty vector transgene d-C. Plants were pre-treated with water or $0.05 \mu \mathrm{m}$ dexamethasone 2 days prior to release of GPA. Leaf samples for RNA extraction were harvested 2 days after infestation of each plant with $20 \mathrm{GPA}$.

(b) Comparison of GPA numbers 2 days after infestation of plants treated as in (a). All values are the means of six plants $\pm \mathrm{SE}$. Analysis of variance (ANOVA) for GPA population was conducted using PROC GLM (SAS Institute). The means were separated using Student's $t$-test $(P<0.05)$. Asterisks indicate significant differences in aphid numbers between the Dex-treated plant and its corresponding water-treated control.

A no-choice test was performed to determine whether SAG101 also contributes to defense against GPA by comparing the numbers of GPA on WT (Col-0), pad4-1, sag101, and pad4-1 sag 101 double mutant plants at $48 \mathrm{hpi}$. As shown in Figure 4(a), GPA numbers on sag 101 were comparable to those on WT. In contrast, the numbers of GPA on pad4-1 sag 101 were significantly higher than on WT and sag101 plants, and statistically comparable to those on pad4-1. SAG101 expression was undetectable in GPA-infested WT Arabidopsis leaves (Figure 3). These results show that SAG101, like EDS1, is dispensable for the PAD4-dependent mechanism in resistance to GPA. Consistent with this conclusion, SAG13 and SAG21 transcripts accumulated to high levels in GPA-infested sag101 mutant plants (Figure S2a), and cell death was prevalent in GPA-infested leaves of the sag101 mutant (Figure S2b).

\section{Discussion}

We provide evidence that a PAD4-dependent mechanism acts within the phloem sieve elements to restrict GPA infestation of Arabidopsis plants. This PAD4-conditioned resistance leads to an accelerated cell-death program (Figures $1 \mathrm{~b}$ and S2b) (Pegadaraju et al., 2005). It also limits the aphid population (Figures $1 \mathrm{c}, 4 \mathrm{a}-\mathrm{c}$ and $5 \mathrm{~b}$ ), and serves as an effective deterrent to aphid feeding (Figure 2a,b and Tables 1 and 2). It is likely that these barriers to aphid feeding derive from PAD4 activity in limiting phloem sap uptake, as monitored by EPG. This activity is a novel molecular feature of PAD4 as it operates independently of EDS1, a component that is indispensable for PAD4 function in leaves against various invasive pathogens (Wiermer et al., 2005).

Despite differences in GPA performance between WT plants of Arabidopsis accessions Col-0, Ws-0 and Ler (Figure $4 \mathrm{a}-\mathrm{c}$ ), the role of $P A D 4$ in plant defense against GPA is conserved in these accessions (Figures 1c, $4 a-c$ and 5b). Significantly, PAD4-modulated resistance to GPA involves both antibiosis (restricting aphid population size) and anti-xenosis (deterring aphid settling and feeding). Antibiosis was evident in the no-choice assay in which the presence of PAD4 limited the size of the GPA population (Figures 1c, $4 a-c$ and $5 b)$. Numbers of GPA were higher on three different pad4 mutants than the corresponding WT plants. Conversely, GPA numbers were lower on transgenic 35S:PAD4 plants that ectopically express $P A D 4$ from the $35 S$ promoter (Figure 1c), as well as plants that conditionally expressed a $P A D 4$ transgene in response to Dex treatment (Figure 5b). A deterrent role for PAD4 towards GPA settling on Arabidopsis was evident in the choice test. When given a choice between the pad4-1 mutant and WT, adult insects preferred pad4-1 (Figure 2a). Insects also preferred the WT plant over the 35S:PAD4 transgenic plant (Figure 2b), consistent with PAD4 determining the extent of anti-xenosis.

Previous comparative analyses of aphid feeding behavior between resistant and susceptible plants using the EPG technique have allowed the elucidation of host mechanisms and identification of specific tissues that are important in resistance to aphids (Bernays and Funk, 2000; Kaloshian et al., 2000; Klingler et al., 2005; Prado and Tjallingii, 1994, 1997, 1999; Reese et al., 1994; Zehnder et al., 2001). Leaf surface features, cell-wall properties and composition of intercellular spaces could affect GPA performance on a plant. These factors should influence the time to first probe, and the total duration of time taken by the aphid to reach a sieve element. No significant differences were observed between the time to first probe, total duration of pathway phase, and time to reach first SEP between WT (Col-0) and pad4-1 mutants (Table 1), or between WT (Ws-0) and 35S:PAD4 plants (Table 2). Based on this observation, we conclude that $P A D 4$ does not significantly alter surface features or cell-wall properties that could contribute towards resistance to GPA. As GPA spent a longer time in SEP on the pad4-1 mutant compared to WT, and a shorter time in SEP on the 35S:PAD4 plant, we propose instead that a PAD4dependent resistance factor or mechanism operates in the phloem. 
The PAD4-dependent resistance could be derived from PAD4 protein expressed within the phloem sieve element or companion cells. Alternatively, PAD4 activation in other tissues by aphids could stimulate a phloem-specific program. Previously, PAD4 was found to be necessary for transmission of mobile signals leading to cell death in the Arabidopsis Isd1 (lesions simulating death1) mutant (Rustérucci et al., 2001). Also, activation of systemic acquired resistance against pathogens, which is dependent on the translocation of a factor(s) primarily through the phloem (Guedes et al., 1980; Kiefer and Slusarenko, 2003; Ross, 1966), requires functional PAD4 (Wiermer et al., 2005; L. Jorda, A. Maldonado, C. Lamb and J. E. Parker, MaxPlanck Institute for Breeding Research, unpublished data). However, the involvement of PAD4 in long-distance signaling associated with systemic acquired resistance is part of an EDS1-regulated pathway (Rustérucci et al., 2001), arguing against it contributing to the resistance in the phloem described here.

We propose that a PAD4-dependent phloem-specific factor limits the total duration of phloem sap ingestion and hence the amount of sap consumed by GPA. During the phloem phase, the insect ingests sap and/or secretes saliva into the sieve element (Prado and Tjallingii, 1994; Tjallingii, 2006). Reduced phloem sap ingestion has been found to be associated with host resistance in several other aphid-plant interactions (Chen et al., 1997; van Helden and Tjallingii, 1993; Kaloshian et al., 2000; Klingler et al., 2005; Mesfin et al., 1992; Paul et al., 1996). Several processes operating individually or in concert could limit phloem sap ingestion by aphids. For example, allelochemicals present in the phloem might limit aphid feeding. PAD4 has been shown to influence the synthesis of antimicrobial indole and phenolic compounds and other as yet structurally uncharacterized signal intermediates in Arabidopsis responses to pathogens (Bartsch et al., 2006; Glazebrook et al., 1997; Jirage et al., 1999; Zhou et al., 1998). The possibility that PAD4 modulates the synthesis of phloem-located compounds that are directly detrimental to GPA cannot be excluded. Changes in the source-sink relationship in response to GPA feeding could also affect phloem sap composition to limit GPA feeding. Alternatively, protein coagulation at aphid feeding sites might result in the plugging of sieve elements, thereby preventing feeding (Kehr, 2006; Will and van Bel, 2006). In Arabidopsis leaves exposed to pathogens or photo-oxidative stress, $P A D 4$ is needed to transduce reactive oxygen species-generated signals leading to cell death (Mateo et al., 2004; Rustérucci et al., 2001). It may be that PAD4 alters the reactive oxygen species composition of the sieve elements. Protein coagulation reactions in sieve elements are sensitive to increases in oxygen concentration (Alosi et al., 1988; Kehr, 2006). Thus, any increase in the level of reactive oxygen species in the sieve elements is likely to induce protein clogging. Whatever the precise biochemical processes involved, $P A D 4$-dependent mechanisms operating in the phloem in response to GPA feeding are effective in limiting aphid infestation.

Genetic and molecular data point to EDS1 as the central molecule in a defense pathway against invasive pathogens that requires the partially redundant signaling functions of PAD4 and SAG101 (Feys et al., 2001, 2005; Lipka et al., 2005). EDS1 mRNA was also induced with similar kinetics to PAD4 in response to GPA infestation (Figure 3). Our finding that EDS1 and SAG101 are dispensable for PAD4-conditioned resistance to GPA in the phloem (Figures $4 a-c$ and $5 b$ ) was therefore unexpected. Previously, it was shown that PAD4 protein is severely depleted in eds 1 mutant leaf extracts, and that all of the detectable PAD4 pool is associated with EDS1 protein (Feys et al., 2005). PAD4 protein may not require EDS1 for its function in aphid resistance in the phloem sieve elements or associated cells, and it will be important to establish whether PAD4 accumulates in cells associated with the phloem even in the absence of EDS1. Alternatively, the small amount of residual PAD4 protein that was observed in leaf extracts of eds 1 mutant plants (Feys et al., 2005) may be sufficient and competent to exert full PAD4 function in aphid resistance. The dispensability of SAG101 in PAD4-conditioned resistance to GPA (Figure 4a) points to different molecular attributes of PAD4 in defense signal relay, as pad4 sag 101 mutants are acutely compromised in resistance to host- and non-host-adapted pathogens (Feys et al., 2005; Lipka et al., 2005).

In conclusion, our results reveal a novel function of PAD4 in phloem-based defense against GPA. The identification of $P A D 4$ as a key modulator of plant aphid resistance will aid the characterization of defense mechanisms that target sap-sucking insects.

\section{Experimental procedures}

\section{Plant cultivation and aphid propagation}

Plants and insects were cultivated at $22^{\circ} \mathrm{C}$ in growth chambers programmed for a $12 \mathrm{~h}$ light $\left(100 \mu \mathrm{E} \mathrm{m} \mathrm{m}^{-2} \mathrm{sec}^{-1}\right)$ and $12 \mathrm{~h}$ dark cycle as previously described (Pegadaraju et al., 2005). A GPA colony was propagated on a 50:50 mixture of commercially available radish (Early Scarlet Globe) and mustard (Florida Broadleaf) plants. Voucher specimens of GPA (\#194) were deposited in the Kansas State University Museum of Entomological and Prairie Arthropod Research. Four-week-old soil-grown Arabidopsis plants at the rosette stage were used for all studies. All experiments were performed at least three times with similar results.

\section{Arabidopsis mutants and transgenic lines}

The pad4-1, sag101-1 and sag101-1 pad4-1 mutants and an eds1 RNAi line in Arabidopsis accession Col-0 (Feys et al., 2005), the pad4-2 and eds 1-2 mutants in accession Ler, and the pad4-5 T-DNA insertion, eds 1-1 and pad4-5 eds 1-1 mutants in accession 
Ws-0 have been described previously (Feys et al., 2001, 2005; Glazebrook et al., 1997). Multiple independent transgenic lines in the pad4-5 background were selected that express a single copy of a PAD4 transgene under the control of the CaMV $35 \mathrm{~S}$ promoter with a C-terminal Strepll tag in the pAMPAT binary vector (Witte et al., 2004). 35S:PAD4 lines 1 and 2 used in this study fully complemented the pad4-5 loss of resistance to Pseudomonas syringae bacteria and to the oomycete pathogen Hyaloperonospora parasitica (data not shown). pad4-5 transgenic lines expressing PAD4 fused to an $\mathrm{N}$-terminal $\mathrm{c}-\mathrm{Myc}_{5}$ epitope tag under the control of a dexamethasone-inducible promoter were created using the pTA7001 vector (Aoyama and Chua, 1997). One transgenic line (denoted d-P4) that exhibited no detectable basal but strong Dex-inducible expression of PAD4, and a control line expressing an empty pTA7001 vector (denoted d-C), were selected for analysis. Line d-P4 in pad4-5 was crossed with pad4-5 eds1-1, and the double mutant expressing homozygous Dex:PAD4 was selected using gene-specific primers.

\section{No-choice and choice tests}

No-choice tests were performed as previously described (Pegadaraju et al., 2005). The numbers of aphids were counted 2 days after release of mature apterous (wingless) insects on each plant.

For the choice test, 20 adult apterous aphids were released on the soil in the center of a $15 \mathrm{~cm}$ wide pot containing one WT and one pad4-1 mutant plant, or one WT and one 35S:PAD4 plant, approximately $4 \mathrm{~cm}$ from the two plants. The numbers of adult GPA on each plant were counted at various time points after release of the insects. GPA numbers on a minimum of four plants of each genotype were analyzed for each time point.

\section{Dexamethasone treatment}

Dexamethasone (Sigma-Aldrich, http://www.sigmaaldrich.com/) was dissolved in $100 \%$ ethanol to make a $30 \mathrm{~mm}$ stock, which was further diluted in water to give a $0.05 \mu \mathrm{m}$ solution. Four-week-old plants were sprayed to run-off with the $0.05 \mu \mathrm{m}$ Dex solution, or with water as control, and covered with a transparent plastic dome. Two days later, the plastic dome was removed, and 20 insects were released on each plant for no-choice assays. RNA for RT-PCR analysis was harvested 2 days after the release of insects.

\section{Histochemistry and microscopy}

Trypan blue staining of leaves was performed as previously described (Rate et al., 1999).

\section{RNA analysis}

Gene-specific PCR primers for ACT8 (At1 g49240), SAG13 (At2 g29350) and SAG21 (At4 g02380) were as previously described (Pegadaraju et al., 2005). Primers PAD4-F (5'-ACCGAGGAACATCAGAGGTAC-3') and PAD4-R (5'-AAATTCGCAATGTCGAGTGGC-3'), EDS1-F (5'-CACCAGATCATGGTCAGCCTC- ${ }^{\prime}$ ) and EDS1-R (5'-TTTTGGGAAGCGTAATCCACC-3'), and SAG101-F (5'-AAGGTTCTGCACTTGGGAAGC- $\left.3^{\prime}\right)$ and SAG101-R (5'-GAGAATGATGGGTTGTTCTCGG - $3^{\prime}$ ) were used for PCR amplification of PAD4 (At3 g52430), EDS1 (At3 g48090) and SAG101 (At5 g14930), respectively. RNA for RT-PCR analysis was extracted from Arabidopsis leaves as previously described (Pegadaraju et al., 2005). A two-step RT-PCR was performed on these samples. Total RNA $(2 \mu \mathrm{g})$ was mixed with oligo(dT) primers (Promega, http://www.promega.com/), and the volume was made up to a total of $15 \mu \mathrm{l}$ with water. This mixture was incubated at $70^{\circ} \mathrm{C}$ for $5 \mathrm{~min}$, and then chilled on ice for 2-3 $\mathrm{min}$. Then, $5 \mu \mathrm{l}$ of M-MLV RT buffer (Promega), $1.25 \mu \mathrm{l}$ dNTP mix (10nM each), $1 \mu \mathrm{l}$ M-MLV reverse transcriptase (Promega) and $2.75 \mu \mathrm{l}$ of water were added to the above mix, and cDNA synthesis allowed to proceed at $37^{\circ} \mathrm{C}$ for $1 \mathrm{~h}$. Aliquots $(1 \mu \mathrm{l})$ of this cDNA were used in the subsequent PCR. PCR conditions were as follows: $95^{\circ} \mathrm{C}$ for $5 \mathrm{~min}$, followed by $25 \mathrm{cycles}$ of $95^{\circ} \mathrm{C}$ for $30 \mathrm{sec}, 60^{\circ} \mathrm{C}$ for $30 \mathrm{sec}$, and $72^{\circ} \mathrm{C}$ for $30 \mathrm{sec}$, with a final extension at $72^{\circ} \mathrm{C}$ for $7 \mathrm{~min}$.

\section{Electrical penetration graph}

The EPG technique (Reese et al., 2000; Tjallingii, 1988; Walker, 2000) was used to study the feeding behavior of aphids. Drops that occur during the EPG analysis allow monitoring of stylet activities such as non-probing (when the style is penetrating plant tissue in a largely intercellular manner), the SEP (when the stylet is located in a sieve element) and the xylem phase (when the stylet is located in the xylem element). A thin gold wire $(2-4 \mathrm{~cm}$ long, $10 \mu \mathrm{m}$ diameter) was glued to the dorsum of the aphid using conductive paint (colloidal silver, Ted Pella Inc.; http://www.tedpella.com), and the other end of the wire was connected to the EPG probe. An output wire from the EPG monitor was inserted into the soil in which the plant was rooted. All plants and insects were held inside a Faraday cage during the recording at an ambient temperature of $22^{\circ} \mathrm{C}$. The feeding behavior of individual aphids was monitored for $8 \mathrm{~h}$. A four-channel GIGA-8 direct current amplifier (Wageningen Agricultural University, Wageningen, The Netherlands) was used for simultaneous recording from four individual aphids on four plants (two channels for the pad4-1 or 35S:PAD4 plant and two for the WT plant). Twenty replications were performed, and waveform recordings obtained were analyzed using the EPG analysis software PROBE 3.0 (W.F. Tjallingii, Wageningen University, Wageningen, The Netherlands). The mean time spent by aphids on various activities was analyzed by the non-parametric Kruskal-Wallis' test $(P<0.05)$ (SAS/STAT Software; http://www.sas.com).

\section{Acknowledgements}

The authors are grateful to Professor Nam-Hai Chua (Rockefeller University, NY) for providing the Dex-inducible vector pTA7001, and Professor James Higgins (Department of Statistics, Kansas State University, KS) for statistical analysis. This work was supported by grants from the Cooperative State Research, Education, and Extension Service, US Department of Agriculture, under agreement 2004-35301-14506, and a grant from the National Science Foundation (MCB0416839). Work by the Parker group was supported by the Gatsby Charitable Foundation and the Biotechnological and Biological Sciences Research Council (Sainsbury Laboratory), the Max-Planck Society, the Alexander von Humboldt Foundation, and a Federal Ministry of Education and Research Trilateral grant (Max Planck Institute for Breeding Research, Cologne, Germany). This is Kansas Agricultural Experimental Station contribution 06-342-J.

\section{Supplementary Material}

The following supplementary material is available for this article online:

Figure S1. EPG waveforms of GPA feeding on a wild-type Arabidopsis plant. 
Figure S2. $E D S 1$ and $S A G 101$ are not required for the activation of $S A G$ expression and cell death in GPA-infested plants.

\section{References}

Alosi, M.C., Melroy, D.L. and Park, R.B. (1988) The regulation of gelation of phloem exudate from Cucurbita fruit by dilution, glutathione, and glutathione reductase. Plant Physiol. 86, 1089-1094.

Aoyama, T. and Chua, N.H. (1997) A glucocorticoid-mediated transcriptional induction system in transgenic plants. Plant J. 11, 605-612.

Bartsch, M., Gobbato, E., Bednarek, P., Debey, S., Schultze, J.L., Bautor, J. and Parker, J.E. (2006) Regulators of salicylic acidindependent EDS1 signaling in Arabidopsis immunity and cell death. Plant Cell, 18, 1038-1051.

Bernays, E. and Funk, D.J. (2000) Electrical penetration graph analysis reveals population differentiation of host-plant probing behaviors within the aphid species Uroleucon ambrosiae. Entomol. Exp. Appl. 97, 183-191.

Blackman, R.L. and Eastop, V.F. (2000) Aphids on the World's Crops: An Identification and Information Guide, 2nd edn. Chichester, UK John Wiley.

Chen, J.Q., Rahbe, Y., Delobel, B., Sauvion, N., Guillaud, J. and Febvay, G. (1997) Melon resistance to the aphid Aphis gossypii: behavioral analysis and chemical correlations with nitrogenous compounds. Entomol. Exp. Appl. 85, 33-44.

Dixon, A.F.G. (1998) Aphid Ecology: An Optimization Approach, 2nd edn. New York: Chapman and Hall.

Falk, A., Feys, B.J., Frost, L.N., Jones, J.D.G., Daniels, M.J. and Parker, J.E. (1999) EDS1, an essential component of $R$ genemediated disease resistance in Arabidopsis has homology to eukaryotic lipases. Proc. Natl Acad. Sci. USA, 96, 3292-3297.

Feys, B.J., Moisan, L.J., Newman, M.A. and Parker, J.E. (2001) Direct interaction between the Arabidopsis disease resistance signaling proteins, EDS1 and PAD4. EMBO J. 20, 5400-5411.

Feys, B.J., Wiermer, M., Bhat, R.A., Moisan, L.J., Medina-Escobar, N., Neu, C., de Cruz-Cabral, A. and Parker, J.E. (2005) Arabidopsis SENESCENCE-ASSOCIATED GENE101 stabilizes and signals within an ENHANCED DISEASE SUSCEPTIBILITY1 complex in plant innate immunity. Plant Cell, 17, 2601-2613.

Glazebrook, J., Zook, M., Mert, F., Kagan, I., Rogers, E.E., Crute, I.R., Houlb, E.B., Hammerschmidt, R. and Ausubel, F.M. (1997) Phytoalexin-deficient mutants of Arabidopsis reveal that PAD4 encodes a regulatory factor and that four $P A D$ genes contribute to downy mildew resistance. Genetics, 146, 381-392.

Guedes, M.E.M., Richmond, S. and Kuc, J. (1980) Induced systemic resistance to anthracnose in cucumber as influenced by the location of the inducer inoculation with Colletotrichum lagenarium and the onset of flowering and fruiting. Physiol. Plant Pathol. 17, 229-233.

He, Y.H. and Gan, S.S. (2002) A gene encoding an acyl hydrolase is involved in leaf senescence in Arabidopsis. Plant Cell, 14, 805-815.

van Helden, M. and Tjallingii, W.F. (1993) Tissue localisation of lettuce resistance to the aphid Nasonovia ribisnigri using electrical penetration graphs. Entomol. Exp. Appl. 68, 269-278.

Jirage, D., Tootle, T.L., Reuber, T.L., Frost, L.N., Feys, B.J., Parker, J.E., Ausubel, F.M. and Glazebrook, J. (1999) Arabidopsis thaliana $P A D 4$ encodes a lipase-like gene that is important for salicylic acid signaling. Proc. Natl Acad. Sci. USA, 96, 13583-13588.

Kaloshian, I., Kinsey, M.G., Williamson, V.M. and Ullman, D.E. (2000) Mi-mediated resistance against the potato aphid Macro siphum euphorbiae (Hemiptera: Aphididae) limits sieve element ingestion. Environ. Entomol. 29, 690-695.
Kehr, J. (2006) Phloem sap proteins: their identities and potential roles in the interaction between plants and phloem-feeding insects. J. Exp. Bot. 57, 767-774.

Kennedy, J.S., Day, M.F. and Eastop, V.F. (1962) A Conspectus of Aphids as Vectors of Plant Viruses. London, UK: Commonwealth Institute of Entomology.

Kiefer, I.W. and Slusarenko, A.J. (2003) The pattern of systemic acquired resistance induction within the Arabidopsis rosette in relation to the pattern of translocation. Plant Physiol. 132, 840-847.

Klingler, J., Creasy, R., Gao, L., Nair, R.M., Calix, A.S., Jacob, H.S., Edwards, O.R. and Singh, K.B. (2005) Aphid resistance in Medicago truncatula involves antixenosis and phloem-specific, inducible antibiosis, and maps to a single locus flanked by NBS LRR resistance gene analogs. Plant Physiol. 137, 1445-1455.

Lipka, V., Dittgen, J., Bednarek, P. et al. (2005) Pre- and post-invasion defenses both contribute to non-host resistance in Arabidopsis. Science, 310, 1180-1183.

Mateo, A., Mühlenbock, P., Rustérucci, C., Chen, C.C., Miszalski, Z., Karpinska, B., Parker, J.E., Mullineaux, P.M. and Karpinski, S (2004) LESION SIMULATING DISEASE 1 is required for acclimation to conditions that promote excess light energy. Plant Physiol. 136, 2818-2830.

Matthews, R.E.F. (1991) Relationships between plant viruses and invertebrates. In Plant Virology, 3rd edn (Matthews, R.E.F., ed.). New York: Academic Press, pp. 520-561.

Mesfin, T., Thottappilly, G. and Singh, S.R. (1992) Feeding behavior of Aphis craccivora (Koch) on cowpea cultivars with different levels of aphid resistance. Ann. Appl. Biol. 121, 493-501.

Miles, P.W. (1987) Feeding process of Aphidoidea in relation to effects on their food plants. In Aphids: Their Biology, Natura Enemies and Control, Vol. 2B (Minks, A.K. and Herrewijn, P., eds). Amsterdam: Elsevier, pp. 321-339.

Miles, P.W. (1999) Aphid saliva. Biol. Rev. 74, 41-85.

Neal, J.J., Tingey, W.M. and Steffens, J.C. (1990) Sucrose esters of carboxylic-acids in glandular trichomes of Solanum berthaultii deter settling and probing by green peach aphid. J. Chem. Ecol. 16, 487-497.

Paul, T.A., Darby, P., Green, C.P., Hodgson, C.J. and Rossiter, J.T. (1996) Electrical penetration graphs of the damson-hop aphid, Phorodon humuli on resistant and susceptible hops (Humulus Iupulus). Entomol. Exp. Appl. 80, 335-342.

Pegadaraju, V., Knepper, C., Reese, J.C. and Shah, J. (2005) Premature leaf senescence modulated by the Arabidopsis thaliana PAD4 gene is associated with defense against the phloemfeeding green peach aphid. Plant Physiol. 139, 1927-1934.

Pollard, D.G. (1973) Plant penetration by feeding aphids (Hemiptera, Aphidoidea): a review. Bull. Entomol. Res. 62, 631-714.

Prado, E. and Tjallingii, W.F. (1994) Aphid activities during sieve element punctures. Entomol. Exp. Appl. 72, 157-165.

Prado, E. and Tjallingii, W.F. (1997) Effect of previous plant infestation on sieve element acceptance by two aphids. Entomol. Exp. Appl. 82, 189-200.

Prado, E. and Tjallingii, W.F. (1999) Effect of experimental stress factors on probing behavior by aphids. Entomol. Exp. Appl. 90 289-300.

Rask, L., Andreasson, E., Ekbom, B., Eriksson, S., Pontoppidan, B. and Meijer, J. (2000) Myrosinase: gene family evolution and herbivore defense in Brassicaceae. Plant Mol. Biol. 42, 93-113.

Rate, D.N., Cuenca, J.V., Bowman, G.R., Guttman, D.S. and Greenberg, J.T. (1999) The gain-of-function Arabidopsis acd6 mutant reveals novel regulation and function of the salicylic acid signaling pathway in controlling cell death, defense, and cell growth. Plant Cell, 11, 1695-1708. 
Reese, J.C., Margolies, D.C., Backus, E.A., Noyes, S., Bramel-Cox, P. and Dixon, A.G.O. (1994) Characterization of aphid host plant resistance and feeding behavior through use of a computerized insect feed monitor. In History, Development, and Application of AC Electronic Insect Feeding Monitors (Ellsbury, M.M., Backus, E.A. and Ullman, D.L., eds). Lanham, MD: Thomas Say Publications in Entomology/Entomological Society of America, pp. 52-72.

Reese, J.C., Tjallingii, W.F., van Helden, M. and Prado, E. (2000) Waveform comparisons among $A C$ and $D C$ electronic monitoring systems for aphid (Homoptera: Aphididae) feeding behavior. In Principles and Applications of Electronic Monitoring and Other Techniques in the Study of Homopteran Feeding Behavior (Walker, G.P. and Backus, E.A., eds). Lanham, MD: Thomas Say Publications in Entomology/Entomological Society of America, pp. 70-101.

Ross, A.F. (1966) Systemic effects of local lesion formation. In Viruses of Plants (Beemster, A.B.R. and Dijkstra, J., eds). Amsterdam: North-Holland, pp. 127-150.

Rustérucci, C., Aviv, D.H., Holt, B.F. III, Dangl, J.L. and Parker, J.E. (2001) The disease resistance signaling components EDS1 and $P A D 4$ are essential regulators of the cell death pathway controlled by LSD1 in Arabidopsis. Plant Cell, 13, 2211-2224.

Tjallingii, W.F. (1988) Electrical recording of stylet penetration activities. In Aphids: Their Biology, Natural Enemies and Control, volume $2 B$ (Minks, A.K. and Harrewijn, P., eds). Amsterdam: Elsevier, pp. 95-108.

Tjallingii, W.F. (2006) Salivary secretions by aphids interacting with proteins of phloem wound responses. J. Exp. Bot. 57, 739-745.

Walker, G.P. (2000) A beginner's guide to electronic monitoring of homopteran probing behavior. In Principles and Applications of Electronic Monitoring and Other Techniques in the Study of Homopteran Feeding Behavior (Walker, G.P. and Backus, E.A., eds). Lanham, MD: Thomas Say Publications in Entomology/ Entomological Society of America, pp. 14-40.

Wiermer, M., Feys, B.J. and Parker, J.E. (2005) Plant immunity: the EDS1 regulatory node. Curr. Opin. Plant Biol. 8, 383-389.

Will, T. and van Bel, A.J.E. (2006) Physical and chemical interactions between aphids and plants. J. Exp. Bot. 57, 729-737.

Witte, C.P., Noël, L.D., Gielbert, J., Parker, J.E. and Romeis, T. (2004) Rapid one-step protein purification from plant material using the eight-amino acid Strepll epitope. Plant Mol. Biol. 55, 135-147.

Zehnder, G.W., Nichols, A.J., Edwards, O.R. and Ridsdill-Smith, J. (2001) Electronically monitored cowpea aphid feeding behavior on resistant and susceptible lupin. Entomol. Exp. Appl. 98, 259-269.

Zhou, N., Tootle, T.L., Tsui, F., Klessig, D.F. and Glazebrook, J. (1998) PAD4 functions upstream from salicylic acid to control defense responses in Arabidopsis. Plant Cell, 10, 1021-1030. 